\title{
Characteristics of Political Discourse during the Election of 28 June 2009 in Albania
}

\author{
Aulona Zotaj ${ }^{1}$ \\ Eva Reveli2
}

${ }^{1}$ Phd Candidate, University of Tirana, History and Philology Faculty

2Phd Candidate, Ministery of Difence, Tirane, Albania

Email: aulonaz@yahoo.com

\section{Doi:10.5901/ajis.2015.v4n2s2p214}

\begin{abstract}
The elections of June 28, were the elections that for the first time in Albania allowed application of powerful political advertising. Given that the two main parties can afford not only to have the volume and an intensity marketing, but also to have reconciled the best experts in the world in this field, named Mark Penn and Arthur Finkelstein as strategists of both parties main. In terms of political message the three main parties which also carries a professional electoral campaign, the Democratic Party, the Socialist Party and the Socialist Movement for Integration, had much better outlined and countoured the campaign lines. In this paper will dwell in analyzing the elements that built the campaign of the main parties in the country.Democratic Party as the ruling party held in most of time a positive message being proud of the government balance until then and highlighting achievements motivate reconfirmation of the mandate. Socialist Party swayed more by negative campaign highlighting problems, failures and scandals of the government of the Democratic Party, while the Socialist Movement for Integration party was based more on an issue like the economic crisis, and the leader of the political force wanting to portray it as a man with a plan.Max Weber says: "At the beginning of this century politics is shifting towards a linguistic war, by distructing public and journalists in this war will affect their writings opinion (Weber 1992: 33-34). In fact, more than a conftonting of political alternatives, the campaign was like a festival where different parties competing to reconcile in an exclusive waz, known artists to organize the the most reachable spectacle.
\end{abstract}

Keyword: Democratic Party, Socialist Movement, Integration party, elections

\section{Introduction}

Politics is momentum when the philosophy becomes active upon its interference in the reality. The lack of the politics which has been accompanied during those recent years, certifies just the philosophic emptiness of our political parties, the mental fading and vacuum that was filled by the political personalization show which looks like the American CatchWrestling-Match, a fake battle realized by, but everybody devoted to watching it. 'Believe that the political discourse must be exceed such standard phase and to take into the consideration any idea or concepts, howsoever must be good, it would be consumed itself metaphysically it cannot be translated into the touchable actions and initiatives, at last in the implemented politics. Mediums, in the post-communist regime, influences sufficiently over the society, always interposing by politics. Medium role politically have been defined equally in the Habbermassian's framework, considering the media as an imported tool of the informative debate, a vital interconnection between the electorates and the selected representative. The political discourse becomes a media tic discourse, thus it earns the new features, weltered and derived within the defined bottom of its new status. The medium and political form of the political discourse makes him standard confirm the intellect and mentality of the Albanian middle class, of the immediate needs for the judges and conjectures, daily opinions and his preconceptions, as well as the same for the Albanian peasants, because there are those who decide democratically and to the principle one member a vote for the avenue of Albania, today and for the future.

The stratus, who at the beginnings of nineties, demands the social changes, were the poorest and they were in the gap of the social expansion of the country. They were ex political persecutors, townie nonemployees, rural areas inhabitants without spaces in the cities and towns, the northerners who were suffering the iniquities of the separation South and North in the homeland territory, the youngers, male and females ones, which were holding on their backs and bones the isolation of the country and wasting of their lives in the otiosity which was too heavy and hard, being everybody the individual with the subdued personality, with frustrated libido, with pressed psychological energy from the social, 
ideological power and politics of the time.

It's understandable, the political communication tongue and language with those stratus, couldn't be calm, vested with the foreign and pretty words, supported by the technician language, expressed without calls and shouts of the meetings orators and speakers, without self-suggested dynamics of the crowds devoted in front of the leader, without charisma, because he is the leader of the human beings mass which had been included in the sea waves of the disparity and hostility, which has been dialed with the terms prison, abduction, torture, ignominy and so on. Nobody can expect to see individuals or groups respecting clearly in absolute way the law enforcement, or legal and cultural norms, which had let them undemocratically in the unjust statement and stage of the repression and suffers undeserved. Nobody can pretend to require appearing the burocratic legalists because they we were distinguished at the scheme of the history to ruin the previous social links, the legal framework and calm language of the politics and jurisprudence that was a symbolic relationship sealed the old social reality."

Radicalism of political language and the articulation of the agglomerations speeches was appointed and defined just on social and psychological formation of the stratus which were removals of social, progress and democratic changes of the lives in our country.

"It's clear enough that the inhabitants are keen and concerned to the politics, but they speak a different language from the politicians. Public personalities are concentrated mainly at the practical issues. They perceive the politics in moral category, thus here, according to my opinion, they can touch only the people issues and subjects. Their politics is different from "principles" of the journalist and politician. Those individuals cannot use other political language because the language of the rational dialog was closed by the previous state and the elites. This was a phenomena occurred by certain decades in the systematic way from the politics in power.

\section{Methodology of work}

The theme "Characteristics of political discourse during 2009th election process in Albania" is a work which demands a serious and voluminous research because the medium, electronica or written ones, are the imperative of the age time and are at the same time, the powerful power of informing the society. So their role has to been not only with the information but with establishing and shaping of the political identities. Hope that beyond the research of that subject, we must draw to the relevant conclusion which coincides with any empiric result.

The method used in this research the method of deduction (from general to the special sites). This research must have the three dimensional form which would support and overlap into three axes: theory, analytic and comparative ones.

\section{Political discourse after June election}

The election of June $28^{\text {th }}$, was the first election which allowed the application vigorously the political publicize. Both main counterparts could be let themselves not only to have the intensity and volume of marketing, but they hired the best and well-known experts of the world for that scope such as Mark Penn and Arthur Finkelstein like the strategist of the two main political parties. In the respect of the political massage of the three main parties, that carried out indeed a professional campaign, the Democratic Party, Socialist Party and the Socialist Movement for Integration had contoured and outlined the campaign frames.

Democratic Party as the party in power, held continuously, most of the time a positive message being proud with the government balance of approaches and achievements, emphasizing everything which could motivate the mandate reconfirmation. The socialist Party leaned mostly from the negative campaign showing and gave to the light the problems and issues, scandals and checkmates of the Democratic Party government. Meanwhile the Socialist Movement for Integration was based upon the economic crisis and was addressed to the political force leader portrayed him as a distinguished man with a plan.

Another characteristic element of the election campaign was the concentration of to the party image and so the political marketing was the lack of ideological and programming contest. Thus, the political party raced and competed with the form not with the content, was fazed with image than massage, with the packing not with the product, centralizing the campaign into different companies and consulters clashes and slams for marketing of the political campaign and made it Americanized in extremes. Max weber is fair when he cites: "That at the beginning of this centry, the politics is deviated to the linguistic war, misleading the public where the journalists could influenced with their editorials and opinions during this wear". (Weber 1992: 33-34).

As matter of fact, more than a political alternatives confrontation, the campaign was as a fest where the parties 
hired and deal with the best and well-known artists for the great spectacles.

Unfortunately, all this professionalism of the campaign was made on backbone of the political game and was not successful to mask the inferlity of the public offer of competitors and the draining of the political admiration for the respective leaders. "Usage of the "troops" is one of the marvelous features of the Greek political discourse. Such creative linguistic sources were not used only to "decorate" the political speeches and to make it attractive for the public, but, more important, was to create and set up the counterpart (ë) and their projects in such aspects of political identity". Our campaign was the same concentrated in the exception and denigration of other political identity, concentrating once more to the forms and political metaphors and not to the contest.

Another aspect of the electoral campaign of 2009, as was mentioned by Anita Fetzer and Elda Weizman were "symbiotic relation". As a result, the political discourse is under continuity with the informalities, daily discussions and talks (Chilton and Schäffner 2002:7). In this contest, the politicians try frequently to exceed the limits of their official roles, social statuses, as well as the linguistic ones, passing to the formal, personalized style and mode attracting over the discourse sources which are not taken into the consideration from their social statuses

Such sources are employed strategically from politicians in their attempts to induce and stimulate a personalized view of the political issue and to set up the illusion of inclusion with the public.

Whole this political campaign not only gave a sound, healthy political solution for the country, allowing both right and left rings with the same number of deputies, "But was not succeed to mobilize truly the electorate participated into the process with $50.77 \%$, meanwhile the three last election process overpassed $72.6 \%$ participation". As matter of fact, intensive presence of the relationship with public, political marketing and advanced campaign technics not only compensate the lack of the political quality offer, but, at the contrary, increase the contrast and make understandable that kind of emptiness.

The current crises in public communication, which has touched a lot of instances and chains of this communication, may be the product of the specific circumstances of the Albanian realm. (can't deny) taking into account that Paul Chilton cited 'language and social behavior combines closely between them, may be like a kind of natural mechanism or as a natural development of the mind mechanism, this, may be, for the reason of the evolutionary adaptation"; meanwhile taking into the consideration the possibility that current realm must be product of this communication or its pathologies. The agents (or subjects) of the political processes are not independent from those processes.

What was issued is the political discourse trends to the charismatic pretension and personal loyalty. In a publication done by Prof. Fuga it was written for the debate personalization as a soft mechanism, because "concentrating to the nonpolitical occurs and behaviors of the counterpart, reciprocally, they are doing the symbolic displacement of the conflict from the dangerous areas of the massive political tension to nonpolitical horizons, such as touching the interests of family, histories of the past, or up to ownership issues etc". This hate language appears and fulminates firstly where the argument is absent. So rarely, the press chronically reflect word to word the vulgar polemics and comebacks, where the argument was replaced by the rhetoric, quarrels with a denigrated and impure vocabulary. 'Devise of a politician into the polemic without any fact or paper is the establishing of the conflictual environment with the arrogant rhetoric". All this indicates a lack of Albanian political culture which we are suffering from the time of Mr. Mithat Frashërit.

"Ironically, old judgment manner inherited from the past regime, expertly the polarized separation of politics at "we" (entrusted supporters of the "correct and proper line" and "they" (the enemies of the people and party) is continuing to be survived". This mentality is the spreading of the passionate discussions of the hateful and personal feud frequently compressed at the reciprocated accusations and charges for the malversations and corruptions, or the links with previous regime, not a calm and logic discussion for the normal policy including al political and social actors, solving the issues which are suffering, creating a full useful discussions agenda and not more aseptic talks, setting up the coalition which would provide the solutions and progress and not more confusion and anarchy, as well as building a compromise in the frame of the procedures and for institutions accepted by them

'There are those reasons that the political actors are represented fragmentary, incoherent and ambitious". In front of the domination of such kind of language, the only solution is acting with coherent concepts such as reaccept of homeland spirit of our distinguished figures, to the elements which are connected such as standard language, the origin, history, and common aspiration. If everybody would like to overpass the internal, fragmentized communication sniff and is using the standard language this is the only and proper solution 


\section{Conclusions}

20 years ago, Robert Fogelin presented a frank assertion. Discourses which are in the deep divergence cannot solve rationally. This assertion, up today is caused a lot of trouble to the augmented theorists. In spite of that, i argue in this work, the discourses that are in the deep divergence, at least, some of them, must be solve rationally along the concept of "Third party".

Political discourse developed by two main leaders of the two huge parties indicates that those discourses were empty and dry without the argumenta element precipitating to an ordinary and charlatan discourse. Political discourse developed mainly by the two leaders indicated that those discourses were empty and dry without argumenta element precipitated so in an ordinary and charlatan discourse. This is the flagrant case when this language not only have decreased the climate at the country, as Prof. fuga cites in one of his article, but has increased the aggravation putting the country in the social, economic and political collapse and jeopardizing, endangering the free movement and entrance of in EU community.

Both parties are doing nothing else only put into their mouths a river full of accusing for each other, no facts but a priory. For sure, immersed into that political slough and hole as Woods called "a dialectic black hole where the negotiation conditions expired" According to Woods such situation would paralyze public discourse and the obstacle is so-called "confrontation of the fifth force". This term is using for disagreements where any part is not taking into the account the country opinions as the real possibility closing the cooperation possibilities.

Both concepts used by Fogel and Wood are adopted for the situation where our country was currently, a situation that has no turns back. Which is naturally the source of this crises and how must be achieved an agreement between them? Once more i shall mention Fogel to understand the origin of this conflict which has its roots to the manner of discourses development between parties.

"A clear answering must be: people who are included in the arguments exchange, are concerned how this argue must be solved. The people can understand a possible disagreement represented, everyone understood, but they are acting so because of the proper interests that they have to solve the argument in their concerns".

The result issued seeing the own concerns for each party is to the prejudice on Albania, when must go forward to the same parameters as other countries of the Balkan region.

Which are the co-operative channels for the politicians can enter into the negotiation? Fogel is pessimist if we can see it for the deep disagreements solutions. This is not true in the moment that the discourse are included more than two direct and indirect present audiences.

It's just the time when can appear and enter to the game a third party role which is important and special for solving of political cramp. The third party is international factor encouraging political actors straight to the dialog road and the cooperation for the general concerns of the country.

Cooperation between all political forces for the majeure issues and national interests is a necessity. I believe at these important moments for the country our relation would not establish over the differences and changes that we have for different subjects, but must set up upon the common objectives, to enable a better life for each Albanian inhabitant, providing a free movement, and reaching the approach of the European dream implemented There are a lot of important subjects which are requiring the cooperation of position and opposite. Certainly it will be good that Albania to solve this Albanian problem without the mediation of the west foreigners. The Albanian authorities are working with reforms for the EU integration. Functioning of the institutions is a basic principle of the democracy and it is imported into the implementation of Copenhagen's criteria. Attempts for solving of such problems cannot be done only for membership into EU. It is imported to have a normal political climate and to serve in good shape and way to our citizens in the country.

\section{References}

Chilton, P. (2004), Analyzing the Political Discourse, theory and practice, Routledge, London and New York, Fuga, A. (2009), Sa i mire debate politik, Botuar ne gazeten "Standart", 5.12.2009

Sinani, G. (2007, Novembre). Shqiperia sot analiza sfida dhe mendesi, Polis Magazine

Duka, V. (2007).Histori e Shqiperise 1912-2000. Tirane, Albania: Kristalina, K-H

Fogelin, R. J. (1985). The Logic of Deep Disagreements. Informal Logic 7: 1-8.

Perelman, C. \& Olbrechts-Tyteca, L. (1969). The new rhetoric: A treatise on argumentation. (Wilkinson, J. and Weaver, P. Trans.). Notre Dame: University of Notre Dame.

Lugg, A. (1992). "Reply: Deep Disagreement and Informal Logic: No Cause for Alarm." Informal Logic, 8.1, 47-51.

Bitzer, L. F. (1968). "The Rhetorical Situation." Philosophy and Rhetoric 1.1: 1-14. 